\title{
Hypomagnesemia and Poor Glycemic Control Among Palestinian Type 2 Diabetic Patients: A Cross-Sectional Study
}

\author{
Mohmmad Hamarshih \\ Palestine Diabetes Institute
}

\section{Suha Hamshari}

An-Najah National University

Zaher Nazzal ( $\sim$ znazzal@najah.edu )

An-Najah National University

\section{Farha Abu Snobar}

An-Najah National University

\section{Rawa Mletat}

An-Najah National University

\section{Ola Abu Mazen}

An-Najah National University

\section{Beesan Maraqa}

Primary Health Directorate, Palestinian Ministry of Health

\section{Research Article}

Keywords: Diabetes Mellitus, Hypomagnesemia, Glycemic control, Palestine.

Posted Date: November 15th, 2021

DOI: https://doi.org/10.21203/rs.3.rs-1066121/v1

License: (9) (i) This work is licensed under a Creative Commons Attribution 4.0 International License. Read Full License 


\section{Abstract}

Background: Hypomagnesemia has been shown to have a significant impact on both glycemic control and diabetes complications in type 2 Diabetes Mellitus (T2DM) patients. This study aims to assess the prevalence of hypomagnesemia in T2DM patients and find the association between serum magnesium levels and outcomes relevant to glycemic control and diabetic complications.

Methods: A cross-sectional study was conducted and included 373 patients (222 males and 151 females). Serum magnesium levels were measured by the Colorimetric Endpoint Method using the Cobas C501system. Hypomagnesemia was determined to be a serum magnesium level $<1.6 \mathrm{mg} / \mathrm{dL}$. In addition, the following data were also obtained; patients' characteristics, anthropometric measurements, smoking status, HbA1c, co-morbidities, and therapeutic management.

Results: Patients' mean age was $56.2 \pm 10.8$ years, $24.6 \%$ were smokers, and most were overweight or obese. About $60 \%$ have a history of hypertension, and the majority have had diabetes for more than ten years. Their mean $\mathrm{HbA} 1 \mathrm{c}$ level was $8.5 \pm 2$. The prevalence of hypomagnesemia was $11 \%(95 \% \mathrm{Cl}$ : 8\%-14.6\%). It was found to be significantly higher among females (adjusted OR: $2.7,95 \% \mathrm{Cl}: 1.2 \%-5.8 \%$ ), patients with $\mathrm{HbA} 1 \mathrm{c} \geq 8 \%$ (adjusted OR: $2.4,95 \% \mathrm{Cl}: 1.1 \%-5.5 \%$ ), and patients with a history of diabetic retinopathy (adjusted OR: 2.7, 95\%Cl: 1.1\%-7.1\%).

Conclusions: the study showed that hypomagnesemia is more prevalent in females and is associated with diabetic retinopathy and poor glycemic control. Having a sufficient magnesium level may be associated with better glycemic control and a reduced occurrence of complications.

\section{Background}

The prevalence of diabetes has been increasing globally over the past few decades. It was estimated to be about $8.4 \%$ in 2017, and the prevalence is predicted to increase to $9.9 \%$, with about 629 million people expected to have the disease by 2045 (1). When it comes to Palestine, diabetes mellitus (DM) is the fourth leading cause of death in the country; the prevalence of T2DM in the West Bank was found to be $9.7 \%$ in 2000 and increased to $15.3 \%$ in 2010 and is projected to increase to $23.4 \%$ by 2030 (2).

Magnesium is considered an essential electrolyte for any living organism and is the fourth most abundant mineral in the human body (3). It serves as a cofactor for over 600 vital enzymatic reactions in the human body and an activator for an additional 200 (4). The depletion of magnesium may result in a defective tyrosine-kinase activity at the insulin receptor level resulting in an impairment of insulin action (5). Magnesium also regulates multiple channels in beta-cells that are involved in insulin secretion. Moreover, insulin receptor autophosphorylation depends on intracellular Mg2+ concentrations, making magnesium a direct and significant contributing factor to insulin resistance. This is linked to the fact that many studies have shown that hypomagnesemia is closely associated with endocrine disorders, particularly type 2 diabetes mellitus (T2DM) (6). It is now believed that diabetes itself is known to induce 
hypomagnesemia, and hypomagnesemia may contribute to the development or worsening of diabetes mellitus (7).

Many studies have reported significantly lower serum magnesium levels in T2DM patients than nondiabetic healthy controls $(8,9)$. Globally, hypomagnesemia's prevalence ranges between $14-48 \%$ among diabetic patients(10-12). Diabetic patients with hypomagnesemia show an accelerated progression of the disease and an increased risk for diabetic complications. This involves macrovascular complications such as cardiovascular and peripheral artery disease (13) and microvascular complications such as retinopathy, nephropathy, and neuropathy $(14,15)$.

The notable increase in the incidence of diabetes and the close relation between metabolic control of diabetes and impaired magnesium balance makes it essential to find the possible association between the two. Identification of hypomagnesemia's prevalence may help justify the need for magnesium level monitoring in patients with T2DM. It can also provide grounds for earlier supplementation with oral magnesium, which may help slow down or prevent diabetes complications. In this study, we aim to investigate the prevalence of hypomagnesemia among patients with T2DM and examine the relationship between serum magnesium levels and glycemic control and diabetic complications

\section{Methodology}

\section{Study design and sampling}

A cross-sectional study was conducted at the Palestine Diabetes Institute (PDI) in West Bank, a charitable non-profit institute that offers early detection, treatment, and follow-up services for diabetic patients. All patients, $\geq 18$ years with T2DM, who attend the Palestine Diabetes Institute, were considered eligible participants. Patients with the following conditions were excluded from the study: type 1 DM, malignancy, acute or chronic diarrhea with dehydration, subjects who were administered Mg supplements or Magnesium-containing antacids within the last three months, dialysis patients, and pregnant women.

The study was approved by the Institutional Review Board (IRB) at An-Najah National University [Ref. Med 11/2019]. Participants were approached and invited to participate voluntarily in the study. We asked those who agreed to participate in signing informed consent. Their identifying information was kept confidential, and the data was used for research purposes only.

The sample size was calculated using a $95 \%$ confidence level and a 0.05 absolute precision. Based on the fact that the prevalence of hypomagnesemia varies between different studies in the region, we assumed the effect size as $50 \%$, which is the maximum variability; and calculated a sample size of 380 participants. A convenient sampling method was used. Data were collected between the 1 st of January and the 1 st of March, 2020. Investigators obtained the required data from the patient's medical records using a data abstraction sheet prepared for the study.

\section{Measurements and Laboratory Analysis}


DM was diagnosed by the PDI, according to the American Diabetes Association (ADA) Classification and Diagnosis of Diabetes 2019(16). We obtained HbA1c readings from medical records using the most recent one in the last three months. The magnesium level was measured by Colorimetric Endpoint Method using Cobas C501system. Results reliability was assured by internal quality- control systems. We defined hypomagnesemia as the occurrence of magnesium levels below $1.6 \mathrm{mg} / \mathrm{dL}(0.66 \mathrm{mmol} / \mathrm{L})$.

Anthropometric measurements, including weight and height, were measured when participants wore light clothing and without shoes. According to their BMI, we categorized patients following the World Health Organization's recommendation adopted by the American Diabetes Association(17). Smoking was classified into three categories: non-smoker; a person who has never smoked before or has smoked in the past but currently does not smoke, light smoker; a person with a smoking history of less than 30 packyear and heavy smoker with 30 or more pack-year smoking history (18).

We obtained the following data from patients' records: history of co-morbidity including hypertension and dyslipidemia, history of diabetic microvascular and macrovascular complications, the patients' age, gender, smoking history, HbA1c level, DM duration, and therapeutic management (diuretics, oral hypoglycemic agents and insulin).

\section{Statistical Analysis:}

SPSS version 21 was used for data entry and analysis. Continuous data were presented as mean \pm standard deviation, and categorical data were expressed as frequency and percentages. We estimated the prevalence of hypomagnesaemia and its $95 \%$ confidence intervals $(\mathrm{Cl})$. Univariable inferential statistics to compare between different groups was conducted using the chi-square test. Statistical significance was set at a P-value of $<0.05$. Additionally, we conducted multivariable logistic regression to assess a given variable's independent effect after adjusting for possible confounders.

\section{Results}

\section{Background characteristics:}

A total of 373 T2DM patients [222 (59.5\%) males and 151 (40.5\%) females] were enrolled in this study. Their age range was between $24-84$ years, with a mean of $56.2( \pm 10.8)$ years. The majority of them were 45- 65 years old (65.4\%). Smoking was reported in 87 (24.6\%) participants, and most of them were either overweight or obese ( $36.8 \%$ and $51.4 \%$, respectively). The patients' mean BMI was $30.9 \pm 5.6$. One-third (33.0\%) of the patients had a duration of diabetes of more than ten years, and $222(59.8 \%)$ have a history of hypertension. For their diabetes management, $263(71.1 \%)$ were on oral hypoglycemic agents without insulin, and $51.1 \%$ had $\mathrm{HbA} 1 \mathrm{c} \geq 8$. The patients' mean $\mathrm{HbA} 1 \mathrm{c}$ level was $8.5 \pm 2$ (Table 1). 
Table 1

Background characteristics of the study participants ( $n=373$ )

\begin{tabular}{|c|c|c|}
\hline Variables & Frequency (\%) & $M e a n \pm S D$ \\
\hline \multicolumn{3}{|l|}{ Gender } \\
\hline Male & $222(59.5 \%)$ & \\
\hline Female & $151(40.5 \%)$ & \\
\hline Age in years & & $56.2 \pm 10.8$ \\
\hline $18-44$ years & $49(13.1 \%)$ & \\
\hline $45-64$ years & $244(65.4 \%)$ & \\
\hline$\geq 65$ years & $80(21.5 \%)$ & \\
\hline \multicolumn{3}{|l|}{ History of HTN } \\
\hline Yes & $222(59.8 \%)$ & \\
\hline No & $149(40.2 \%)$ & \\
\hline \multicolumn{3}{|l|}{ Smoking } \\
\hline Non-Smoker & $256(74.6)$ & \\
\hline Light smoker & $29(8.5 \%)$ & \\
\hline Heavy smoker ${ }^{\star}$ & $58(16.9 \%)$ & \\
\hline \multicolumn{3}{|l|}{ BMI } \\
\hline Normal (BMI <25) & $44(11.9)$ & \\
\hline Overweight (BMI 25<30) & $136(36.8 \%)$ & \\
\hline Obese $(\mathrm{BMI} \geq 30)$ & $190(51.4 \%)$ & \\
\hline \multicolumn{3}{|l|}{ DM DURATION } \\
\hline$<10$ Years & $250(67 \%)$ & \\
\hline$\geq 10$ Years & $123(33 \%)$ & \\
\hline \multicolumn{3}{|l|}{ DM management } \\
\hline Oral hypoglycemic agents alone & $263(71.1 \%)$ & \\
\hline OHA combined with insulin & $107(28.9 \%)$ & \\
\hline $\mathrm{HbA1c}$ & & $8.5 \pm 2.5$ \\
\hline$<8$ & $180(48.9 \%)$ & \\
\hline$\geq 8$ & $188(51.1 \%)$ & \\
\hline
\end{tabular}




\section{Variables \\ Frequency (\%) Mean $\pm S D$ \\ * Smoking history of $\geq 30$ pack-years \\ Hypomagnesaemia and associated factors}

The prevalence of hypomagnesaemia was $11 \%(n=41)$ [95\% Cl: $8 \%-14.6 \%]$. The univariable analysis showed that hypomagnesemia was significantly more prevalent among female patients $(17.2 \%)$ compared to males (6.8\%), P-value $=0.002$. On the other hand, no association was found with age, smoking, and BMI (Table 2).

Table 2

Patients demographic characteristics with hypomagnesemia

\begin{tabular}{|c|c|c|c|c|}
\hline \multirow[t]{2}{*}{ Characteristic } & \multicolumn{2}{|c|}{ Hypomagnesaemia } & \multirow[t]{2}{*}{ Total } & \multirow[t]{2}{*}{ P-value* } \\
\hline & Yes $(n=41)$ & No $(n=332)$ & & \\
\hline \multicolumn{5}{|l|}{ Gender } \\
\hline Male & $15(6.8 \%)$ & $207(93.2 \%)$ & $222(100 \%)$ & 0.002 \\
\hline Female & $26(17.2 \%)$ & $125(82.8 \%)$ & $151(100 \%)$ & \\
\hline \multicolumn{5}{|l|}{ Age in years } \\
\hline 18-44 years & $6(12.2 \%$ & $43(87.8 \%)$ & 49 (13.1\%) & 0.923 \\
\hline 45-64 years & $27(11.1 \%)$ & $217(88.9 \%)$ & $244(65.4 \%)$ & \\
\hline$\geq 65$ years & $8(10.0 \%)$ & $72(90.0 \%)$ & $80(21.4 \%)$ & \\
\hline \multicolumn{5}{|l|}{ Smoking } \\
\hline Non-smoker & $34(29.1 \%)$ & $222(86.7 \%)$ & $256(100 \%)$ & 0.149 \\
\hline Light smoker & $1(3.4 \%)$ & $28(96.6 \%)$ & $29(100 \%)$ & \\
\hline Heavy smoker & $4(6.9 \%)$ & $54(93.1 \%)$ & $58(100 \%)$ & \\
\hline \multicolumn{5}{|l|}{ BMI } \\
\hline Normal & $1(2.3 \%)$ & 43(97.7\%) & $44(100 \%)$ & 0.15 \\
\hline Overweight & $17(12.5 \%)$ & 119(87.5\%) & $136(100 \%)$ & \\
\hline Obese & $23(12.1 \%)$ & $167(87.9 \%)$ & $190(100 \% 0$ & \\
\hline
\end{tabular}

Hypomagnesemia was reported among $14.9 \%$ of patients with $\mathrm{HbA} 1 \mathrm{c} \geq 8$ compared to $7.2 \%$ of patients with $\mathrm{HbA} 1 \mathrm{c}<8$. This difference was found to be significant $(P=0.019)$. We found a significant higher proportion of hypomagnesemia among diabetic neuropathy patients $(19.5 \%)$ and diabetic retinopathy patients $(8.9 \%)(P$ value $=0.008$ and $=0.006$, respectively). No significant correlation was found between 
hypomagnesemia and HTN status, DM duration, DM management, history of diabetic nephropathy, and history of macrovascular complications, dyslipidemia, and diuretics. (Table 3) 
Table 3

Patients clinical characteristics with hypomagnesemia

\begin{tabular}{|c|c|c|c|c|}
\hline \multirow[t]{2}{*}{ Characteristic } & \multirow[t]{2}{*}{ Total } & \multicolumn{2}{|c|}{ Hypomagnesaemia } & \multirow[t]{2}{*}{ P-value* } \\
\hline & & Yes $(n=41)$ & No $(n=332)$ & \\
\hline \multicolumn{5}{|l|}{ HTN } \\
\hline Yes & $222(100 \%)$ & $29(13.1 \%)$ & 193(86.9\%) & \multirow[t]{2}{*}{0.131} \\
\hline No & $149(100 \%)$ & $12(8.1 \%)$ & 137(91.9\%) & \\
\hline \multicolumn{5}{|l|}{ DM duration } \\
\hline$<10$ Years & $250(100 \%)$ & $25(10 \%)$ & $225(90 \%)$ & \multirow[t]{2}{*}{0.38} \\
\hline$\geq 10$ Years & $123(100 \%)$ & $16(13 \%)$ & 107(87\%) & \\
\hline \multicolumn{5}{|l|}{ HbA1c } \\
\hline$<8$ & $180(100 \%)$ & $13(7.2 \%)$ & $167(92.8 \%)$ & \multirow[t]{2}{*}{0.019} \\
\hline$\geq 8$ & $188(100 \%)$ & $28(14.9 \%)$ & $160(85.1 \%)$ & \\
\hline \multicolumn{5}{|l|}{ DM management } \\
\hline Combination with insulin & $107(100 \%)$ & $12(11.2 \%)$ & $95(88.8 \%)$ & \multirow[t]{2}{*}{1.00} \\
\hline Oral hypoglycemic agents alone & $263(100 \%)$ & $29(11 \%)$ & $243(89 \%)$ & \\
\hline \multicolumn{5}{|l|}{ History of Diabetic Nephropathy } \\
\hline Yes & $164(100 \%)$ & $19(11.6 \%)$ & $145(88.4 \%)$ & \multirow[t]{2}{*}{0.601} \\
\hline No & $153(100 \%)$ & $15(9.8 \%)$ & $138(90.2 \%)$ & \\
\hline \multicolumn{5}{|l|}{ History of Diabetic neuropathy } \\
\hline Yes & $77(100 \%)$ & $15(19.5 \%)$ & $62(80.5 \%)$ & \multirow[t]{2}{*}{0.008} \\
\hline No & $296(100 \%)$ & $26(8.8 \%)$ & $270(91.2 \%)$ & \\
\hline \multicolumn{5}{|l|}{ History of Diabetic retinopathy } \\
\hline Yes & $44(100 \%)$ & $10(22.7 \%)$ & $34(77.3 \%)$ & \multirow[t]{2}{*}{0.006} \\
\hline No & $271(100 \%)$ & $24(8.9 \%)$ & $247(91.1 \%)$ & \\
\hline \multicolumn{5}{|c|}{ History of Macrovascular complications } \\
\hline Yes & $57(100 \%)$ & $9(15.8 \%)$ & $48(84.2 \%)$ & \multirow[t]{2}{*}{0.212} \\
\hline No & $315(100 \%)$ & $32(10.2 \%)$ & $283(89.8 \%)$ & \\
\hline
\end{tabular}




\begin{tabular}{|c|c|c|c|c|}
\hline \multirow[t]{2}{*}{ Characteristic } & \multirow[t]{2}{*}{ Total } & \multicolumn{2}{|c|}{ Hypomagnesaemia } & \multirow[t]{2}{*}{$P$-value* } \\
\hline & & Yes $(n=41)$ & No $(n=332)$ & \\
\hline Yes & $326(100 \%)$ & $37(11.3)$ & $289(88.7 \%)$ & 0.198 \\
\hline No & $13(100 \%)$ & $0(0 \%)$ & $13(100 \%)$ & \\
\hline \multicolumn{5}{|c|}{ Diuretics therapy } \\
\hline Yes & $63(100 \%)$ & $9(14.3 \%)$ & $54(85.7 \%)$ & 0.321 \\
\hline No & $309(100 \%)$ & $31(10 \%)$ & 278(90\%) & \\
\hline
\end{tabular}

\section{Multivariable analysis of factors associated with hypomagnesemia}

Multivariable logistic regression was conducted to adjust for confounders and assess the independent factors associated with hypomagnesemia. Gender, $\mathrm{HbA1c}$ level, and history of diabetic retinopathy remain significantly associated with hypomagnesemia. Female patients were 2.7 times more likely to have hypomagnesemia than male patients ( $\mathrm{P}$-value $=0.015$, adjusted $\mathrm{OR}=2.7,95 \% \mathrm{Cl}: 1.2 \%-5.8 \%$ ). Likewise, patients who had $\mathrm{HbA} 1 \mathrm{c} \geq 8 \%$ were 2.4 times more likely to have hypomagnesaemia in comparison to those with $\mathrm{HbA} 1 \mathrm{c}<8 \%$ (P-value $=0.04$, adjusted $\mathrm{OR} 2.4,95 \% \mathrm{Cl}: 1.1 \%-5.5 \%$ ). Furthermore, those who had a history of diabetic retinopathy were 2.7 times more likely to have hypomagnesemia than those without a history of diabetic retinopathy [P-value $=0.04$, adjusted $\mathrm{OR}=2.7,95 \% \mathrm{Cl}: 1.1 \%-7.1 \%)$. (Table 4) 
Table 4

Multivariable model of factors independently associated with hypomagnesemia

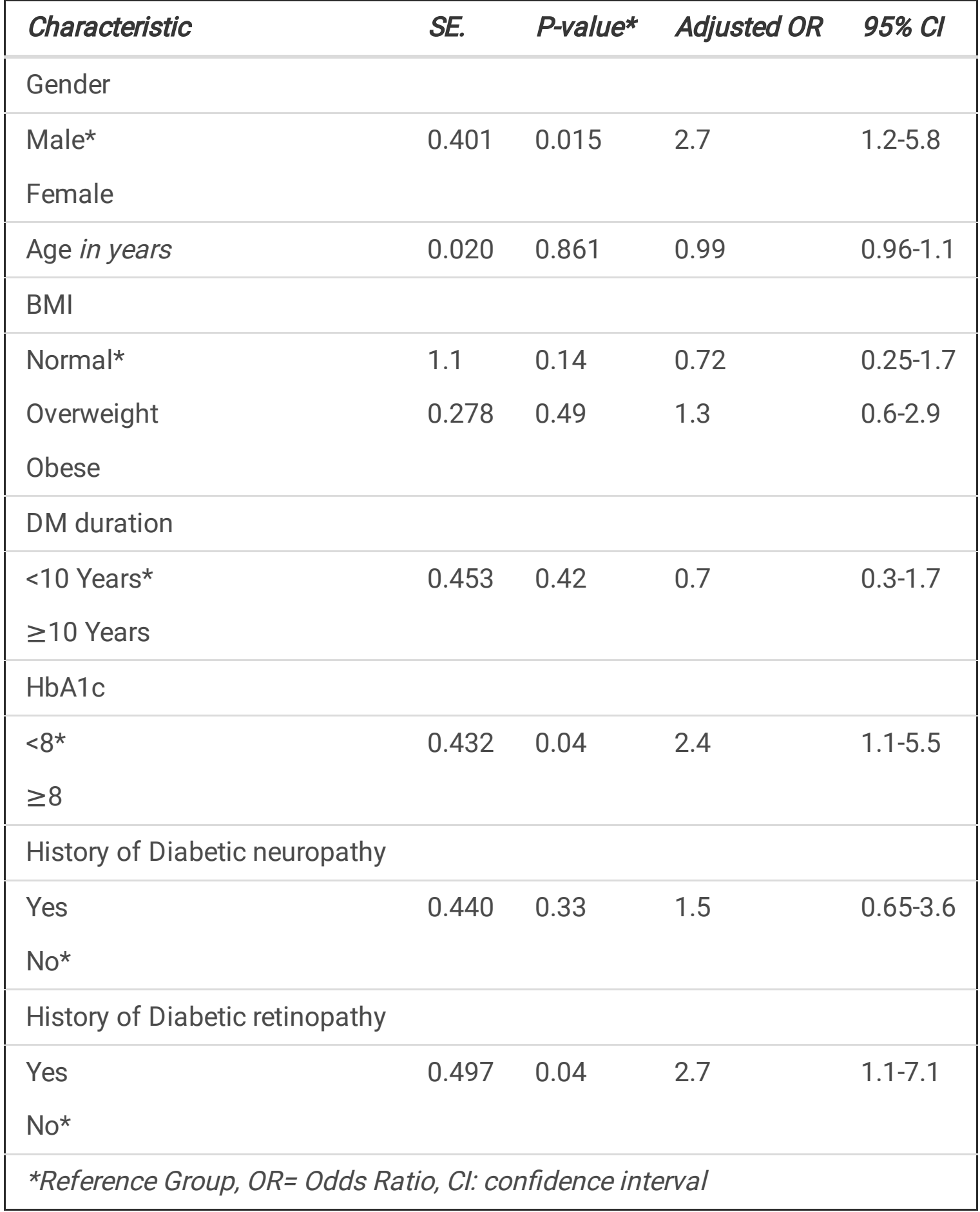

\section{Discussion}

Serum magnesium level and its correlation with DM, have been the subject of significant research and review. However, data relevant to this subject are lacking in Palestine. In this study, hypomagnesemia was found in $11 \%$ of T2DM patients ( $95 \% \mathrm{Cl}, 8 \%-14.6 \%$ ), which is slightly lower than the worldwide prevalence of hypomagnesemia among T2DM patients that varies from 14 to $48 \%(12,19,20)$. 
Our results are consistent with the findings of several previously conducted studies. For instance, Waanders et al. (12) showed that hypomagnesemia was present in $9.6 \%$ of T2DM patients. Furthermore, Dasgupta et al. observed in an Indian study that hypomagnesemia was found in $11 \%$ of diabetes patients (21). Other studies, such as Saeed et al., indicated a lower prevalence of hypomagnesemia among T2DM patients, which was found to be $5 \%$ (22).

It is observed that a wide range of variance in the prevalence of hypomagnesemia in the different studies does exist, which might be due to a difference in the techniques of magnesium measurements, the cutoff point for defining hypomagnesemia, diversity of the targeted populations, and dietary habits of every particular region. Other explanations could be related to differences in the severity of T2DM cases, and stricter exclusion criteria followed in some studies.

The increased incidence of hypomagnesemia among patients with T2DM is seemingly multifactorial. Possible causes include decreased intake, diabetic gastroparesis, diarrhea as a result of autonomic dysfunction, enhanced renal magnesium loss, glomerular hyperfiltration, osmotic diuresis resulting from glycosuria, metabolic acidosis, and reduced renal reabsorption due to insulin resistance, as insulin enhances reabsorption of magnesium from the loop of Henle $(19,23,24)$.

Hypomagnesaemia was more prevalent for women (17.5\%) than men $(6.8 \%)$ in our sample population. This result is consistent with findings from other studies. Hyassat et al. (24) showed that female patients were more likely to have hypomagnesemia than male patients. These findings were further emphasized in a study conducted by Bertinato et al. (25), which found that serum magnesium was lower in female subjects than in male subjects, regardless of race. The low magnesium intake could explain the higher percentage of hypomagnesemia in females by females regarding their physiological needs, use of birth control pills, menstrual cycle, pregnancy, and breastfeeding, all of which could also account for the gender difference in magnesium concentrations.(26).

Another important finding of this study is the significant association between hypomagnesemia and $\mathrm{HbA1}$ c level ( $\mathrm{p}$-value $=0.019$ ). Hypomagnesaemia was reported among $14.9 \%$ of patients with $\mathrm{HbA} 1 \mathrm{c}$ of $\geq 8 \%$, compared to $7.2 \%$ of patients with $\mathrm{HbA} 1 \mathrm{c}$ less than $8 \%$. This finding emphasizes the inverse relation between magnesium level and glycemic control level, which was documented by several previously conducted studies $(6,11,19,21,24)$.

Concerning microvascular complications, a significant relationship between hypomagnesemia and diabetic retinopathy was observed. Multiple studies have documented an association between hypomagnesemia and diabetic retinopathy $(13,20,27,28)$. These showed that serum magnesium levels are significantly lower in patients with diabetic retinopathy than diabetic patients without this type of microvascular complication.

\section{Strengths and Limitations:}


This is the first study in Palestine to assess magnesium level among diabetes patients and correlate it with glycemic control and diabetic complications. In addition to that, the study also covered the three main geographic areas in the West-Bank. Some limitations should be acknowledged. First, the study's cross-sectional nature does not show a causal relationship; prospective studies might be more effective in investigating the effect of magnesium on diabetic control and complications. Second, participants were recruited using a convenient sampling procedure that may limit the generalizability. Third, magnesium occurs in very small quantities in blood, and it does not always reflect the intracellular magnesium level. An estimate of the intracellular magnesium level would allow a better assessment of the magnesium status. Lastly, participants were treated with anti-diabetic, antihypertensive drugs, lipidlowering agents, proton pump inhibitors, and over-the-counter medications, all of which may have affected the results.

\section{Conclusions}

The prevalence of hypomagnesemia in Palestinian T2DM patients is consistent with that of many countries. Hypomagnesemia was positively associated with diabetic retinopathy and poor glycemic control. Periodic magnesium level testing and effective magnesium replacement therapy are recommended to help control diabetes and minimize the risk of long-term complications.

Hypomagnesaemia was also found to be more prevalent in women, which may indicate the need to receive $\mathrm{Mg}$ supplementation in that particular group. A long-term prospective study is required to examine the effect of magnesium replacement on clinical outcomes.

\section{Abbreviations}

ADI American Diabetes Association

$\mathrm{Cl} \quad$ Confidence Intervals

DM Diabetes Mellitus

IRB Institutional Review Board

OR Odds Ratios

PDI Palestine Diabetes Institute

T2DM Type Two Diabetes Mellitus.

\section{Declarations}

Ethics approval and consent to participate: The An-Najah National University institutional review board approved the study. All subjects involved in the study were invited to participate on a voluntary basis after the study purpose, risk, and advantage of participation were clarified. Informed consent was obtained 
from all participants. Interviews were carried out in accordance with the Code of Ethics of the World Medical Association (Declaration of Helsinki).

Consent for publication: Not applicable

Data Availability: The dataset supporting the conclusions of this article is included within the article and its additional file.

Competing Interest: The authors declare that they have no competing interests in this section.

Funding: No funding was received for conducting this study.

Authors' contributions: $\mathrm{ZN}$ and $\mathrm{MH}$ conceived the idea and study design, supervised data collection, data analysis, manuscript writing. $\mathrm{MH}, \mathrm{SH}, \mathrm{FA}, \mathrm{RM}, \mathrm{OA}$, and $\mathrm{MB}$ performed the material preparation, data collection, and analysis. All authors discussed and interpreted the results. The first draft of the manuscript was written by $\mathrm{ZN}, \mathrm{MH}$, and BM. All authors commented on previous versions of the manuscript. All authors read and approved the final manuscript.

Acknowledgments: Researchers are grateful to the Palestine Diabetes Institute and An-Najah National University for facilitating the research. We would also like to recognize the assistance of PDI physicians in the clinics where we conducted the study. Finally, we are thankful to the study participants.

\section{References}

1. Cho NH, Shaw JE, Karuranga S, Huang Y, Rocha JD, Ohlrogge AW, et al. IDF Diabetes Atlas: Global estimates of diabetes prevalence for 2017 and projections for 2045. Diabetes Res Clin Pract. 2018,138:271-81.

2. Abu-Rmeileh NME, Ghandour R, Mataria A, Awawda S, Jabr S, O'Flaherty M. Time to act on diabetes mellitus prevention in the West Bank, oPt: Current and future direct cost of diabetes and its complications. Obes Med [Internet]. 2017,6:18-22. Available from: http://www.sciencedirect.com/science/article/pii/S2451847617300167

3. Nasri H. Consequences of hypomagnesemia in type 2 diabetes mellitus patients. 2014,3(4):99-100.

4. de Baaij JHF, Hoenderop JGJ, Bindels RJM. Magnesium in Man: Implications for Health and Disease. Physiol Rev. 2015,95(1):1-46.

5. Garg MK. Relation of magnesium with insulin resistance and inflammatory markers in subjects with known Coronary artery disease. J Cardiovasc Dis Res. 2014,(May):21-9.

6. Ramadass S, Basu S, Srinivasan AR. Serum magnesium levels as an indicator of status of Diabetes Mellitus type 2. Diabetes Metab Syndr Clin Res Rev. 2015,9(1):42-5.

7. Feng J, Wang H, Jing Z, Wang Y, Cheng Y, Wang W, et al. Role of Magnesium in Type 2 Diabetes Mellitus [Internet]. Vol. 196, Biological Trace Element Research. Humana Press Inc., 2020 [cited 2020 Nov 18]. p. 74-85. Available from: https://link.springer.com/article/10.1007/s12011-019-01922-0 
8. Kim DJ, Xun P, Liu K, Loria C, Yokota K, Jacobs DR, et al. Magnesium intake in relation to systemic inflammation, insulin resistance, and the incidence of diabetes. Diabetes Care [Internet]. 2010 Dec [cited 2020 Nov 18],33(12):2604-10. Available from: /pmc/articles/PMC2992198/?report=abstract

9. Pham PCT, Pham PMT, Pham S V., Miller JM, Pham PTT. Hypomagnesemia in patients with type 2 diabetes [Internet]. Vol. 2, Clinical Journal of the American Society of Nephrology. Clin J Am Soc Nephrol, 2007 [cited 2020 Nov 18]. p. 366-73. Available from: https://pubmed.ncbi.nlm.nih.gov/17699436/

10. Gommers LMM, Hoenderop JGJ, Bindels RJM, de Baaij JHF. Hypomagnesemia in Type 2 Diabetes: A Vicious Circle? Diabetes [Internet]. 2016 Jan 1,65(1):3 LP - 13. Available from: http://diabetes.diabetesjournals.org/content/65/1/3.abstract

11. Pokharel DR, Khadka D, Sigdel M, Yadav NK, Kafle R, Sapkota RM, et al. Association of serum magnesium level with poor glycemic control and renal functions in Nepalese patients with type 2 diabetes mellitus. Diabetes Metab Syndr Clin Res Rev. 2017,11:S417-23.

12. Waanders F, Dullaart RPF, Vos MJ, Hendriks SH, van Goor H, Bilo HJG, et al. Hypomagnesaemia and its determinants in a contemporary primary care cohort of persons with type 2 diabetes. Endocrine. 2020,67(1):80-6.

13. Lu J, Gu Y, Guo M, Chen P, Wang H, Yu X. Serum Magnesium Concentration Is Inversely Associated with Albuminuria and Retinopathy among Patients with Diabetes. J Diabetes Res. 2016,2016.

14. Arpaci D, Tocoglu AG, Ergenc H, Korkmaz S, Ucar A, Tamer A. Associations of serum Magnesium levels with diabetes mellitus and diabetic complications. Hippokratia. 2015,19(2):153-7.

15. Zhang Y, Li Q, Xin Y, Lv W, Ge C. Association between serum magnesium and common complications of diabetes mellitus. 2018,26.

16. American Diabetes Association. 2. Classification and diagnosis of diabetes: Standards of medical care in diabetes-2019. Diabetes Care [Internet]. 2019 Jan 1 [cited 2020 Nov 18],42(Suppl 1):S13-28. Available from: https://pubmed.ncbi.nlm.nih.gov/30559228/

17. Ulijaszek S. Obesity: Preventing and Managing the Global Epidemic. Report of a WHO Consultation. WHO Technical Report Series 894. Pp. 252. (World Health Organization, Geneva, 2000.) SFr 56.00, ISBN 92-4-120894-5, paperback. J Biosoc Sci. 2003 Oct 1,35:624-5.

18. NHIS - Adult Tobacco Use - Glossary [Internet]. [cited 2020 Nov 18]. Available from: https://www.cdc.gov/nchs/nhis/tobacco/tobacco_glossary.htm

19. Joy SS, George TP, Siddiqui K. Low magnesium level as an indicator of poor glycemic control in type 2 diabetic patients with complications. Diabetes Metab Syndr Clin Res Rev. 2019,13(2):1303-7.

20. Kumar P, Bhargava S, Agarwal P, Garg A, Khosla A. Association of serum magnesium with type 2 diabetes mellitus and diabetic retinopathy. J Fam Med Prim Care [Internet]. 2019 [cited 2020 Nov 18],8(5):1671. Available from: /pmc/articles/PMC6559114/?report=abstract

21. Dasgupta A, Saikia U, Sarma D. Hypomagnesemia in type 2 diabetes mellitus. Indian J Endocrinol Metab. 2012,16(6):1000. 
22. Saeed H, Haj S, Qasim B. Estimation of magnesium level in type 2 diabetes mellitus and its correlation with HbA1c level. Endocrinol Diabetes Metab. 2019,2(1):e00048.

23. Hospital GG. University Journal of Pre and Para Clinical Sciences. Univ J Pre Para Clin Sci ISSN. 2017,3(2):1-3.

24. Hyassat D, Al Sitri E, Batieha A, El-Khateeb M, Ajlouni K. Prevalence of hypomagnesaemia among obese type 2 diabetic patients attending the National Center for Diabetes, Endocrinology and Genetics (NCDEG). Int J Endocrinol Metab. 2014,12(3):1-7.

25. Bertinato J, Xiao CW, Ratnayake WMN, Fernandez L, Lavergne C, Wood C, et al. Lower serum magnesium concentration is associated with diabetes, insulin resistance, and obesity in South Asian and white Canadian women but not men. Food Nutr Res. 2015,59(March).

26. Syedmoradi L, Ghasemi A, ZahediasI S, Azizi F. Prevalence of hypo- and hypermagnesemia in an Iranian urban population. Ann Hum Biol. 2011,38(2):150-5.

27. Kauser M, Afreen A, Kasi J. Study of Serum Magnesium Levels in Diabetic Retinopathy. J Res Med Dent Sci. 2014,2(3):19.

28. Kundu D, Osta M, Mandal T, Bandyopadhyay U, Ray D, Gautam D. Serum magnesium levels in patients with diabetic retinopathy. J Nat Sci Biol Med [Internet]. 2013 Jan [cited 2020 Nov 18],4(1):113-6. Available from: /pmc/articles/PMC3633259/?report=abstract 